\title{
Meta-analysis of the effects of overexpression of WRKY transcription factors on plant responses to drought stress
}

Yuan Guo, Wenjing Ping, Jingtang Chen, Liying Zhu, Yongfeng Zhao, Jinjie Guo and Yaqun Huang* (D)

\begin{abstract}
Background: The tryptophan-arginine-lysine-tyrosine (WRKY) transcription factors play important roles in plants, allowing them to adapt to environmental conditions that are not normally conducive to plant growth; in particular, drought. There has been extensive research on WRKY transcription factors and the effects of their overexpression in plants on resistance to drought stress. However, due to the materials (the type and species of donor and receptor, promoters) and treatments (the type and time of stress) used, different and often confounding results have been obtained between studies. Meta-analysis is a powerful statistical tool that can be used to summarize results from numerous independent experiments on the same research topic while accounting for variability across experiments.

Results: We carried out a meta-analysis of 16 measured parameters that affect drought resistance in plants overexpressing WRKY transcription factors and wild-type plants. We found that only one of these parameters was significantly different between transgenic and wild-type plants under drought and control conditions at a 95\% confidence interval $(p=0.000, p=0.009$, respectively). Eleven of the sixteen parameters were obviously different in WRKY transgenic plants under drought and control conditions (SV, $p=0.023, \mathrm{SSC}, p=0.000, \mathrm{SOD}, p=0.012$, SFW, $p=0.000, \mathrm{RL}, p=0.016$, Pro, $p=0.000, \mathrm{POD}, p=0.027, \mathrm{MDA}, p=0.000, \mathrm{H}_{2} \mathrm{O}_{2}, p=0.003, \mathrm{EL}, p=0.000, \mathrm{CHC}, p=0.000$, respectively), seven of the eleven obviously different parameters showed positive effect (SSC, SOD, Pro, POD, MDA, $\mathrm{H}_{2} \mathrm{O}_{2}, \mathrm{EL}$ ), four of them revealed negative effect (SV, SFW, RL, CHC).
\end{abstract}

Conclusion: We have found that only one of these parameters was significantly different between transgenic and wild-type plants under drought and control conditions respectively, at a 95\% confidence interval. And eleven of sixteen parameters showed obviously different of WRKY-overexpressed plants under different conditions (waterstressed and normal), suggesting that WRKY transcription factors play an important role in plant responses to drought stress. These findings also provide a theoretical basis for further study of the role of WRKY transcription factors in the regulation of plant responses to environmental stress.

Keywords: Drought, WRKY transcription factors, Over-express, Meta-analysis

\footnotetext{
* Correspondence: hyqun@hebau.edu.cn

Hebei Branch of Chinese National Maize Improvement Center, Hebei

Agricultural University, Baoding, People's Republic of China
}

(c) The Author(s). 2019 Open Access This article is distributed under the terms of the Creative Commons Attribution 4.0 International License (http://creativecommons.org/licenses/by/4.0/), which permits unrestricted use, distribution, and reproduction in any medium, provided you give appropriate credit to the original author(s) and the source, provide a link to the Creative Commons license, and indicate if changes were made. The Creative Commons Public Domain Dedication waiver (http://creativecommons.org/publicdomain/zero/1.0/) applies to the data made available in this article, unless otherwise stated. 


\section{Background}

Drought is a type of dehydration stress and largely restricts crop productivity and quality. Improving crop tolerance to drought stress is an effective strategy for the promotion of sustainable agriculture in most crop production regions worldwide [1]. There has been extensive research on plant responses to drought stress at the morphological [2-6], physiological [2, 7-15], and biochemical [16-21] levels. Almost 2000 drought-responsive genes have been identified in Arabidopsis under progressive soil drought stress [22]. Stress gene responses occur primarily at the transcription level; however, the temporal and spatial expression patterns of specific stress genes is an important aspect of the plant stress response [23].

A large number of transcription factors that are either up-or down-regulated in response to environmental perturbations have been identified using genome-wide transcriptome analyses [24, 25]. The tryptophan-argininelysine-tyrosine (WRKY) transcription factor family is one of the largest families of transcriptional regulators in plants and plays important roles in plant development and various stress responses [26]. Several studies have showed that WRKY transcription factors are involved in plant drought stress responses. For example, when Muhammad et al. overexpressed CmWRKY10 from Chrysanthemum, the gene was highly up-regulated in transgenic Chrysanthemum under drought stress through the abscisic acid (ABA) signaling pathway [27]. Overexpression of the grape gene VvWRKY11 in Arabidopsis seedlings increased tolerance to mannitol-induced water stress [28]. Wu et al. overexpressed OsWRKY11 under the control of the HSP101 promoter in transgenic rice and found that it enhanced drought tolerance [29], with reduced leaf wilting and increased survival of green tissues. Overexpression of maize ZmWRKY58 in rice increased the plant survival rate and relative water content (RWC), suggesting that ZmWRKY58 overexpression enhances tolerance to drought and salt stresses in transgenic rice [30]. Similarly, Ding et al. [31] and $\mathrm{Xu}$ et al. [32] both overexpressed WRKY genes in wheat and found that the transgenic plants were more tolerant to water stress than wild-type (WT) plants. The important role played by WRKY transcription factors in plant resistance to drought stress has been increasingly verified across plant species. However, many of the results of these studies are confounded by differences in the species and treatments used. Therefore, there is a need to integrate a large number of studies to allow better interpretation of their results. In this study, we conducted a meta-analysis of the effects on WRKY transcription factors in plant responses to drought stress.

Meta-analysis is a powerful statistical tool that can be used to summarize results from multiple independent experiments while accounting for variability across experiments [33]. The applications of meta-analytical approaches are extensive. Meta-analysis has been used to examine the responses of different crop species to biotic and/or abiotic stresses; for example, heat stresses in nitrogen pools. It has also been widely used to examine plant adaptions to abiotic stress. Wang et al. used a meta-analysis of published data to quantitatively evaluate the effects of drought stress on the morphophysiological and biochemical characteristics, growth and biomass partitioning, and yield formation of different wheat ploidies [34]. They found that domestication and selection of higher ploidy wheat has reduced the adverse effects of drought stress on yield and yield components, optimized biomass allocation toward higher seed yields, and reduced stress-related physiological and biochemical responses. Ma et al. [35] and Augé et al. [36] used metaanalyses to explore responses to $\mathrm{NaCl}$ stress; namely, the regulation of the main cation/proton antiporter gene and arbuscular mycorrhizal symbiosis, respectively. These studies provided a reference for further investigations of plant responses to salt stress. Dong et al. conducted a meta-analysis of plants overexpressing DREB transcription factors and found that of 13 measured parameters, 8 and 2 exhibited significant transcriptional responses in drought-stressed and control plants, respectively.

When plants are subjected to drought stress, they respond by adapting to the environmental conditions. The comprehensive response to drought that occurs in plants encompasses changes to their morphology and anatomy, and physiological and biochemical modifications that occur at many different levels; ranging from individual cells, to photosynthetic organs, to the entire structure of the plant [37]. An overall assessment of drought tolerance can be determined by measuring plant growth and yield; however, specific morphological, anatomical, physiological, and biochemical parameters can also serve as indicators of plant responses to stress [38]. In this study, we used an integrated analysis of 16 physiological and morphological plant parameters that were measured across a relatively large number of studies. These included the plant survival rate, soluble sugar content, superoxide dismutase (SOD) activity, peroxidase (POD) activity, catalase (CAT) activity, $\mathrm{H}_{2} \mathrm{O}_{2}$ content, shoot fresh weight, stomatal aperture, RWC, root length, proline content, plant height, germination rate, electrolyte leakage, chlorophyll content and malondialdehyde content.

\section{Results}

\section{Summary of overall effects}

Our meta-analysis included 158 studies published in 47 journal articles. These contained 19 species, including 6 monocots and 13 dicots. 5 gramineous plants, 3 legume plants, 2 solanaceae plants, 2 compositae plants, and 9 
other types of plants. A number of the response variables commonly measured in plants as adaptations to drought stress were listed in Fig. 1. The cauliflower mosaic virus CaMV35S promoter was most widely used (109 studies). The two most commonly appeared recipient species were Arabidopsis and tobacco (69 and 58 studies, respectively), and almost all were dicots (153 studies). Most of the studies introduced a single foreign WRKY gene (140 studies), although some introduced two genes (18 studies). Two-thirds of the gene donor species were dicots (96 studies).

One of the 16 measured plant parameters was obviously different between transgenic and WT plants subjected to drought stress conditions at a 95\% confidence interval (survival rate; Fig. 1a). Three parameters were significantly or close to significantly different at a 90\% confidence interval (root length, plant height and soluble sugar content; Fig. 1a). Under non-stressed conditions, 1 of the 16 measured plant parameters was significant at a 95\% confidence interval (RWC), and 1 parameter was obviously different at a close-to-90\% confidence interval (soluble sugar content; Fig. 1b).

To better evaluate the role of WRKY transcription factors in plant resistance to drought stress, we compared transgenic plants under drought and normal conditions (Fig. 2). Eleven of the 16 measured plant parameters had significant differences $(p \leq 0.05)$ : 7 parameters were increased with drought treatment (soluble sugar content, proline content, malondialdehyde content, electrolyte leakage, $\mathrm{H}_{2} \mathrm{O}_{2}$ content, SOD activity and POD activity) and 4 parameters were reduced (survival rate, shoot fresh weight, root length and chlorophyll content). Among of them, the soluble sugar content of transgenic plants changed most (339.1\%) under drought stressed environment, compared with nonstressed condition.

\section{Subgroup analysis of the survival rates of plants under drought conditions}

The specific effects of overexpressing WRKY genes on survival rates of plants subjected to drought conditions were significant when WRKY expression was driven by the CaMV35S promoter (Fig. 3). Different type of stress also contributed to the results, when transgenic plants treated with application of mannitol and without watering, it had significantly enhanced survival rates. If the gene donor and recipient species are from two different genera, it was hypothesized that overexpression of WRKY transcription factors might increase the survival rate. However, the species and type of gene donor had little effect. When the recipient species was a dicot, the transgenic plants showed improved survival. While due to the small number of studies included, there was only one study used monocot species as recipient and effect sizes resulted too large confidence intervals and a low level of precision (Fig.3f).

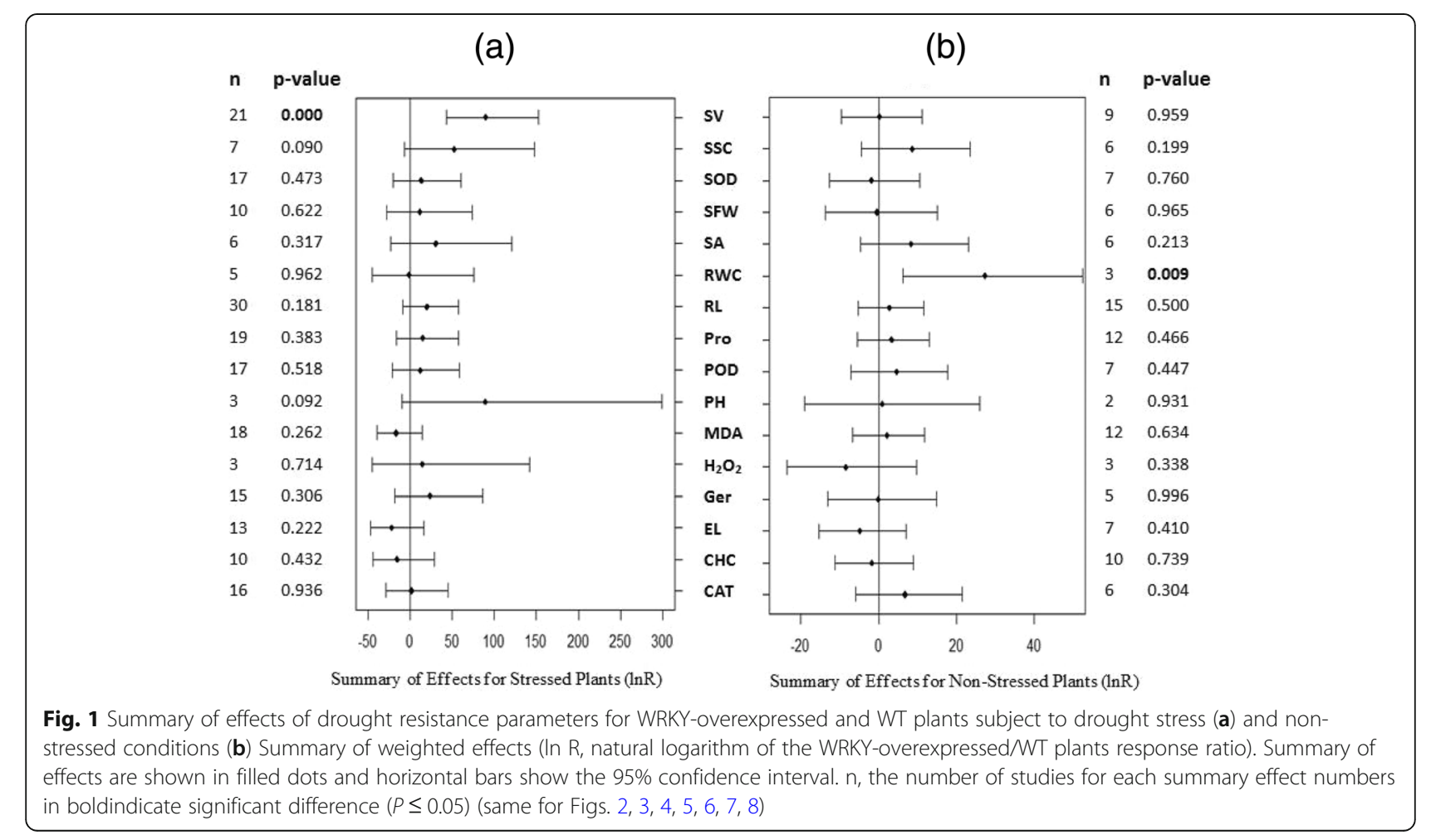




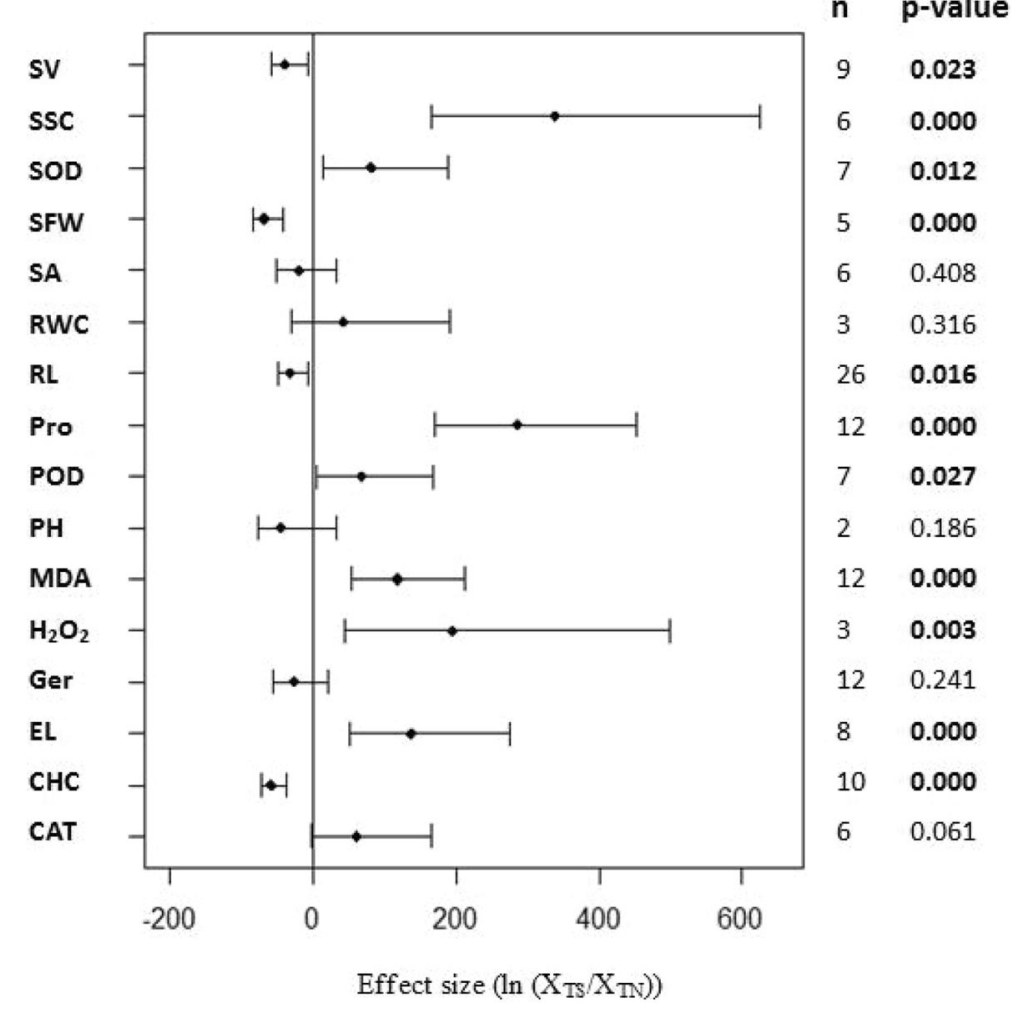

Fig. 2 Summary of effects of drought resistance parameters for WRKY-overexpressed plants under drought-stressed/non-stressed conditions. Weighted summary effect sizes (In ( $\left.\mathrm{X}_{\mathrm{TS}} / \mathrm{X}_{\mathrm{TN}}\right)$, natural logarithm of the WRKY-overexpressed plants under stressed /non-stressed conditions response ratio; $X_{T S}$, the means of WRKY-overexpressed plants under stressed conditions; $X_{T N}$, the means of WRKY-overexpressed plants under non-stressed conditions)

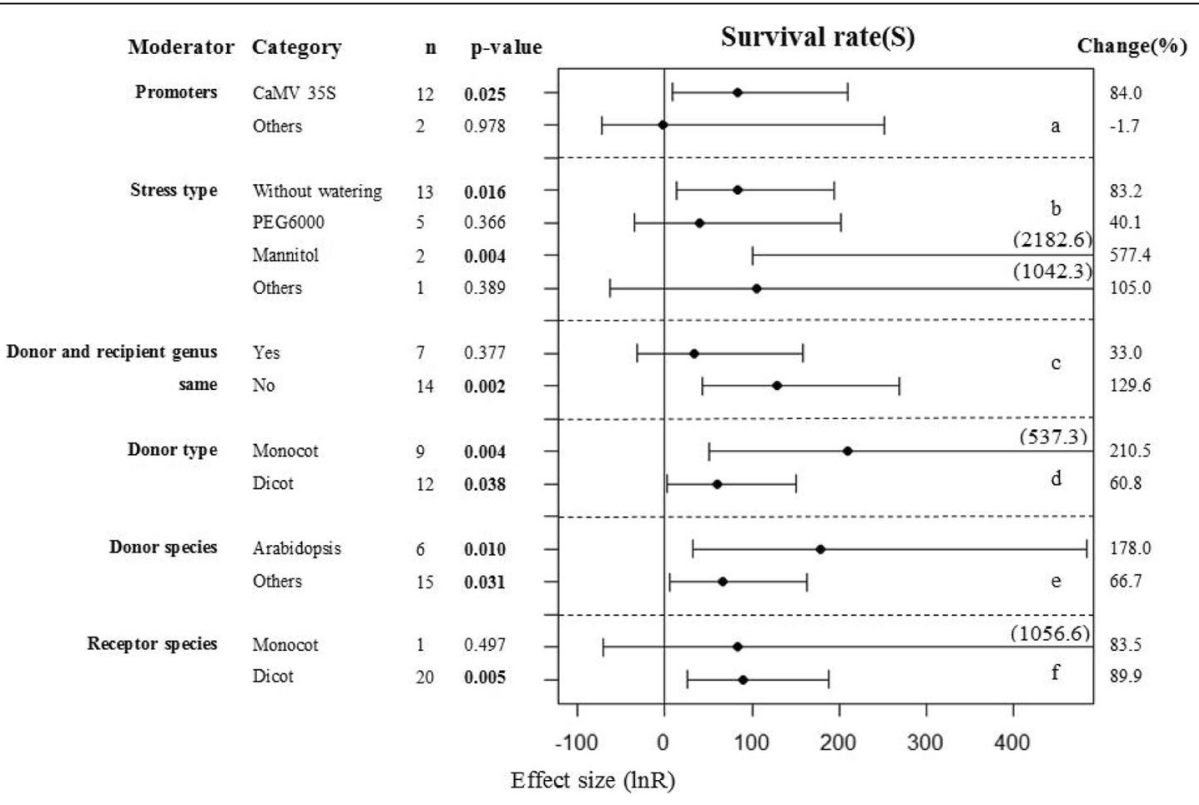

Fig. 3 Subgroup analysis of the effects on survival rate of plants under drought-stressed condition. There are six moderators on survival rate in plants subject to drought (a-f) and category represents each moderator level 


\section{Subgroup analysis of the root lengths of plants under drought conditions}

The transgenic plants did not show any significant differences in their root lengths under drought conditions at a $95 \%$ confidence interval $(p=0.181$; Fig. 1$)$. However, the confidence interval was close to $90 \%$, indicating an almost $90 \%$ confidence that WRKY transcription factors enhanced the root lengths of transgenic plants when water was in limited supply. Because the root length sample size was relatively large, we were able to further explore the factors affecting WRKY transcription factor expression and the root lengths of these transgenic plants (Fig. 4). Different exposure times and types of stress did not affect the results (Fig. 4a, b). A significantly greater positive moderator effect was observed when the gene donor and recipient were from the same genus than when the donor and recipient were from the different genus.(Fig. 4c). When the recipient was from a species other than Arabidopsis, the transgenic plants had significantly increased root lengths (Fig. 4d). When the transgenic plants had two WRKY genes introduced, their beneficial effects on root lengths were more pronounced (Fig. 4f). However, the type of donor did not have an obvious difference between transgenic and WT plants (Fig. 4e).

Subgroup analysis of the soluble sugar contents of plants under drought conditions

The soluble sugar contents of transgenic and WT plants under drought and control conditions were different $(p=0.09$ and $p=0.199$, respectively, Fig. 1$)$. In contrast to the control conditions, use of different treatment media and recipient species with drought stress conditions increased the soluble sugar content in the transgenic plants over that of the WT plants (Figs. 5a, $\mathrm{f}$ and $8 \mathrm{a}, \mathrm{e})$. When promoters other than CaMV35S were used together with drought conditions, significant differences were found for the transgenic plants of the WT plants (Fig. 5c). Obviously differences were also detected when the gene donor species was a monocot (Fig. 5d, e). However, these differences were not significant under non-stressed conditions (Fig. 8b, c, d). Together, these results show that under drought conditions different types of stress can increase the soluble sugar contents in transgenic plants over those of WT plants (Fig. 5b).

\section{Subgroup analyses of the RWC and plant heights of plants under drought conditions}

The heights of the transgenic and WT plants under drought conditions was significantly different at a $90 \%$ confidence interval ( $p=0.092$, Fig. 1). The RWCs of the transgenic and WT plants under control conditions were significantly different at a 95\% confidence interval ( $p=$ 0.009, Fig. 1). When the treatment media was solid medium, mannitol drought stress was applied, the recipient species was Arabidopsis, and the gene donor was a monocot species; the transgenic plants showed increased heights in comparison with the WT plants (Fig. 6a, b, c, d). Seeding age prior to treatment and the gene donor species used had no effect on the RWCs between the transgenic and WT plants under drought conditions (Fig. 7a, b).

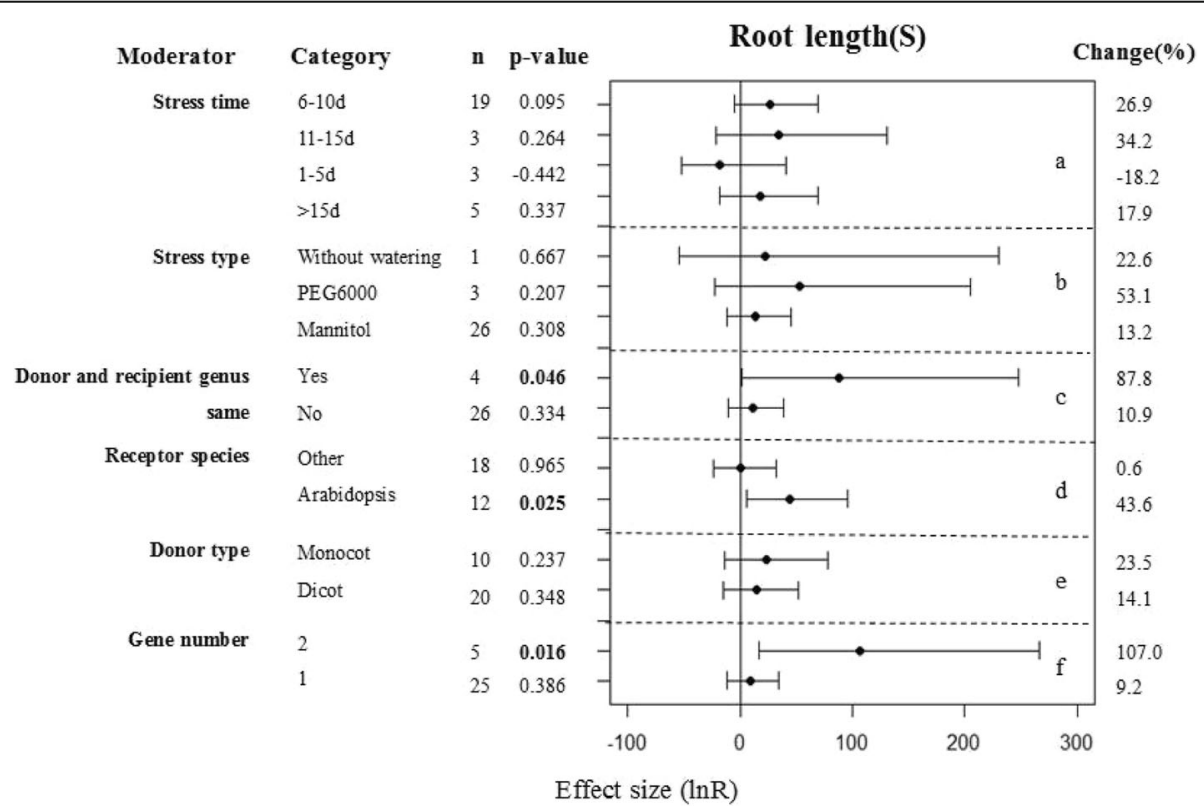

Fig. 4 Subgroup analysis of the effects on root length of plants under drought-stressed condition. There are six moderators on root length in plants subject to drought (a-f) and category represents each moderator level 


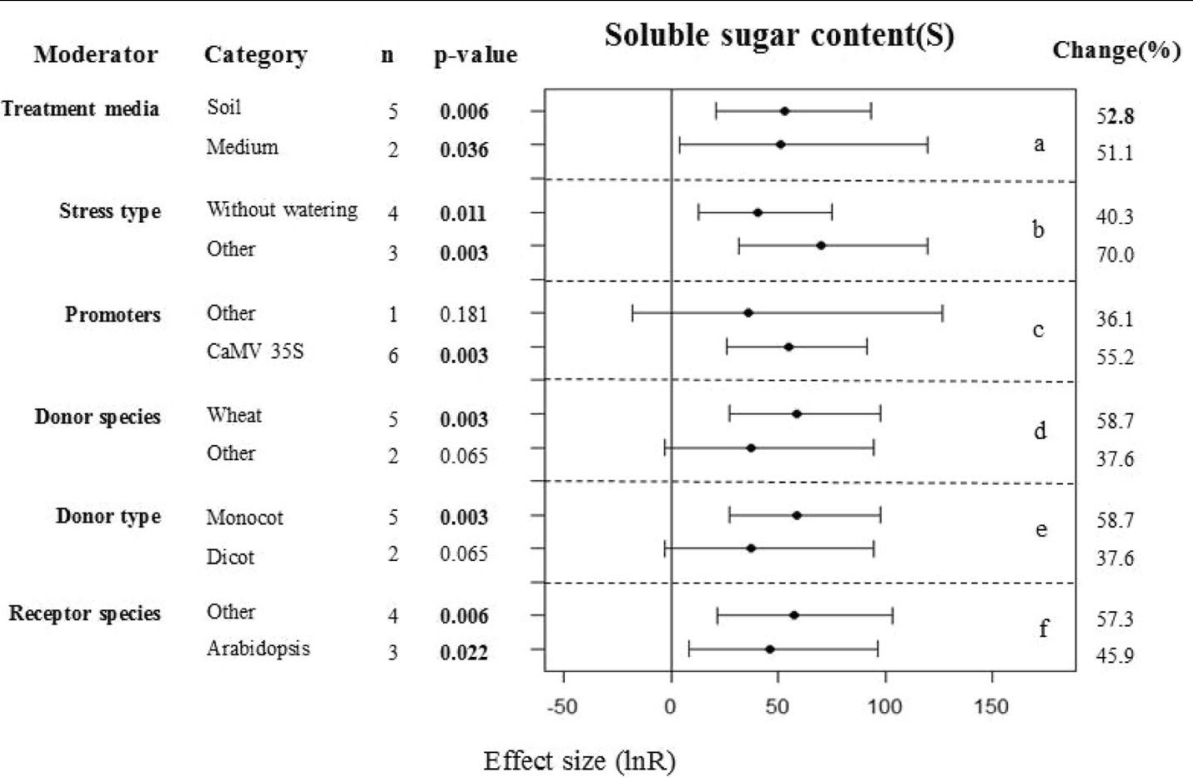

Fig. 5 Subgroup analysis of the effects on soluble sugar content of plants under drought-stressed condition. There are six moderators on soluble sugar content in plants subject to drought (a-f) and category represents each moderator level

\section{Heterogeneity}

Tables 1 and 2 present the heterogeneity statistics of the summary effect sizes of the 16 parameters under different environmental conditions after data conversion (the log ratio of transgenic and WT plants). Additional file 2: Table S1 and Additional file 3: Table S2 (presented in supplementary materials) present the results before the data conversion (the difference between the transgenic and WT plants). The heterogeneity $p$-values were significant $(p<0.10)$ for 2 of the 16 summary effect sizes (Fig. 1), and these also had positive $I^{2}$ values for the malondialdehyde content $\left(p=0.03, I^{2}=49.8 \%\right)$ and the soluble sugar content $\left(p=0.00, I^{2}=82.5 \%\right)$ for plants under non-stressed conditions (Table 1). Eleven of the summary effect sizes had $I^{2}$ values of $0 \%$, and three of the effect sizes had a small positive of $I^{2}$-value but the $p$-value

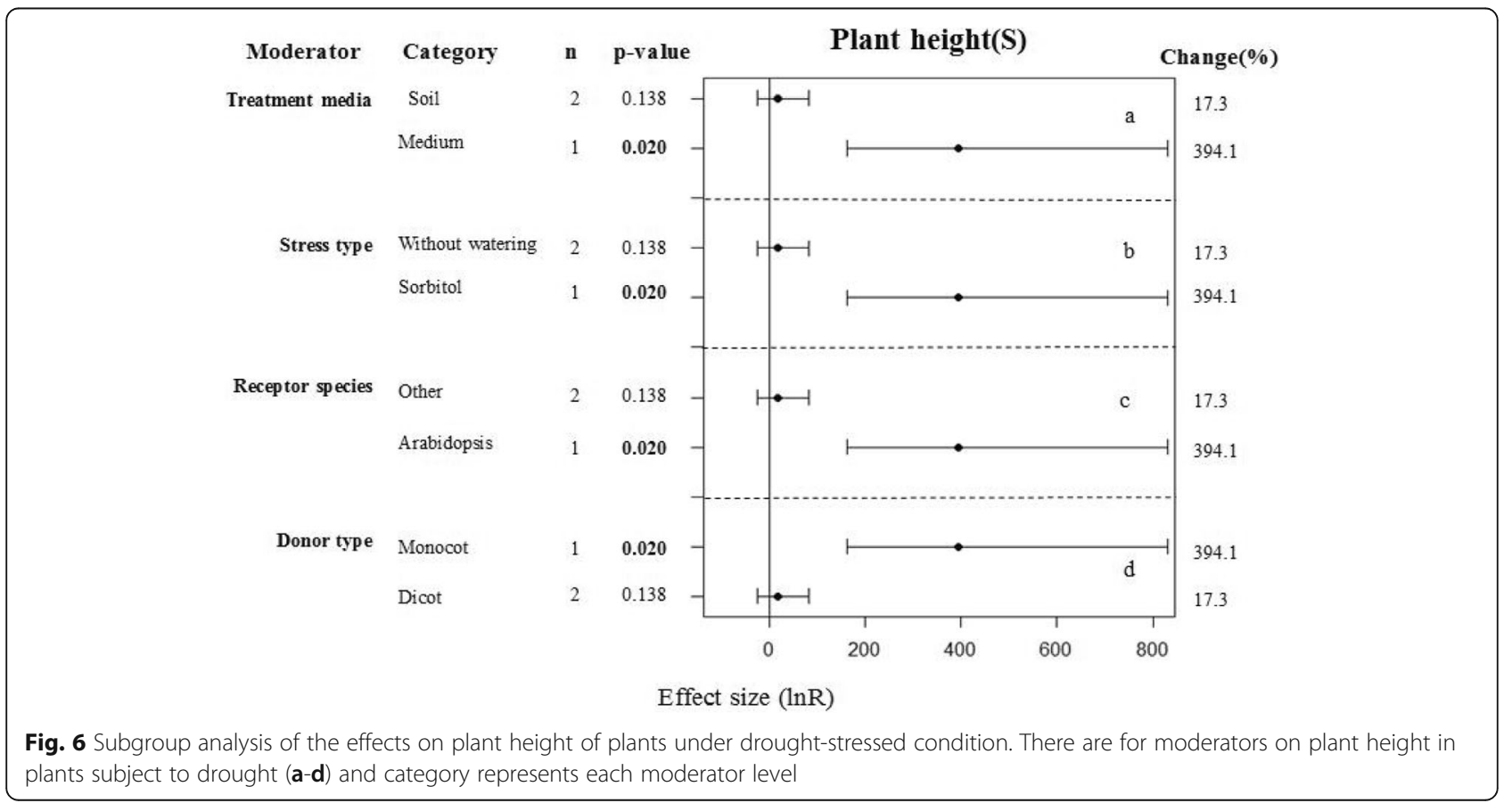




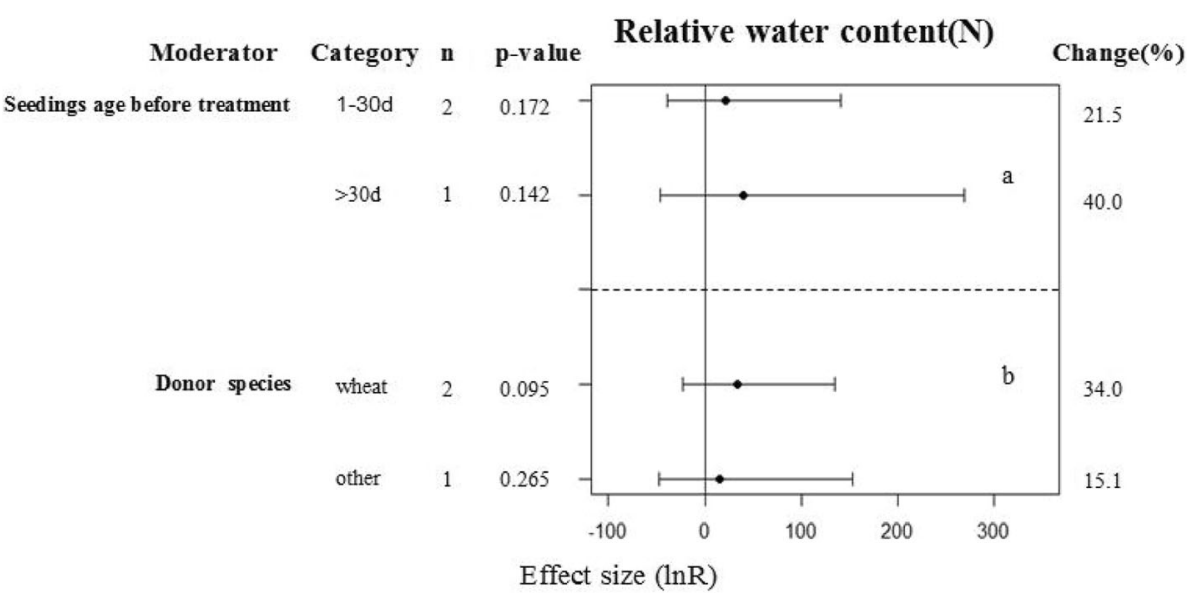

Fig. 7 Subgroup analysis of the effects on RWC of plants under non-stressed condition. There are two moderators on relative water content in plants in control (a-b) and category represents each moderator level

did not show significant heterogeneity $(p>0.10)$. When the true effect sizes differ between studies, the source of this real or true heterogeneity is often further investigated using moderator or subgroup analysis. We conducted a moderator analysis on the effect of the soluble sugar content which was detected as significantly different in Fig. 1a $(p=0.090)$, and the result of moderator analysis showed that transgenic and WT plants under normal conditions were significantly different at a near-to- $90 \%$ confidence interval (Fig. 8). The heterogeneity of the $p$-values was

Table 1 Heterogeneity statistics for the 16 summary effect sizes under non-stressed condition after data conversed

\begin{tabular}{llll}
\hline Trait & Qt & $P$ & $P^{2}(\%)$ \\
\hline Survival rate & 0.00 & 1.00 & 0.0 \\
Stomatal aperture & 0.01 & 1.00 & 0.0 \\
Germination & 0.03 & 0.98 & 0.0 \\
Root length & 7.12 & 0.93 & 0.0 \\
Shoot fresh weight & 0.11 & 1.00 & 0.0 \\
Relative water content & 0.01 & 1.00 & 0.0 \\
Electrolyte leakage & 7.37 & 0.29 & 18.6 \\
Proline content & 1.10 & 1.00 & 0.0 \\
Malondialdehyde content & $\mathbf{2 1 . 9 1}$ & $\mathbf{0 . 0 3}$ & $\mathbf{4 9 . 8}$ \\
Chlorophyll content & 13.31 & 0.15 & 32.4 \\
Soluble sugar content & $\mathbf{2 8 . 5 1}$ & $\mathbf{0 . 0 0}$ & $\mathbf{8 2 . 5}$ \\
Plant height & 0.00 & 0.95 & 0.0 \\
$\mathrm{H}_{2} \mathrm{O}_{2}$ content & 2.24 & 0.33 & 10.8 \\
CAT activity & 0.44 & 0.99 & 0.0 \\
POD activity & 0.06 & 1.00 & 0.0 \\
SOD activity & 0.02 & 1.00 & 0.0 \\
\hline
\end{tabular}

Qt total heterogeneity, $P$ probability that Qt was due entirely to sampling error and not to variation among true effects, $P^{2}$ percentage of heterogeneity due to variation among true effects; Summary effect sizes showing significant heterogeneity among true effects $(p \leq 0.1)$ were shown in bold (Same for Table 2) significant $(p<0.10)$ and the summary effects also had positive $I^{2}$ values for 3 of the 16 summary effect sizes presented in Fig. 1: root length $\left(p=0.00, I^{2}=67.1 \%\right)$, malondialdehyde content $\left(p=0.02, I^{2}=48.6 \%\right)$ and chlorophyll content $\left(p=0.00, I^{2}=82.8 \%\right)$ of drought-stressed plants (Table 2). Twelve of the summary effect sizes had $I^{2}$ values of $0 \%$, and one effect size had a small positive $I^{2}$ value but there was no significant heterogeneity $(p>0.10)$. We conducted a moderator analysis on the effects of root length that were detected as different in Fig. 1a, and found significant differences between the transgenic and WT plants under drought conditions at a near-to- $90 \%$ confidence interval (Fig. 4). Before the data were converted, the

Table 2 Heterogeneity statistics for the 16 summary effect sizes under drought stressed condition after data conversed

\begin{tabular}{llll}
\hline Trait & Qt & P & $P^{2}(\%)$ \\
\hline Survival rate & 1.06 & 1.00 & 0.0 \\
Stomatal aperture & 0.05 & 1.00 & 0.0 \\
Germination & 0.07 & 1.00 & 0.0 \\
Root length & $\mathbf{8 5 . 0 8}$ & $\mathbf{0 . 0 0}$ & $\mathbf{6 7 . 1}$ \\
Shoot fresh weight & 6.78 & 0.66 & 0.0 \\
Relative water content & 0.21 & 0.99 & 0.0 \\
Electrolyte leakage & 10.15 & 0.52 & 0.0 \\
Proline content & 1.93 & 1.00 & 0.0 \\
Malondialdehyde content & $\mathbf{2 9 . 1 8}$ & $\mathbf{0 . 0 2}$ & $\mathbf{4 8 . 6}$ \\
Chlorophyll content & $\mathbf{4 6 . 4 2}$ & $\mathbf{0 . 0 0}$ & $\mathbf{8 2 . 8}$ \\
Soluble sugar content & 0.31 & 1.00 & 0.0 \\
Plant height & 2.75 & 0.25 & 27.4 \\
$\mathrm{H}_{2} \mathrm{O}_{2}$ content & 0.17 & 0.92 & 0.0 \\
CAT activity & 6.39 & 0.93 & 0.0 \\
POD activity & 1.99 & 1.00 & 0.0 \\
SOD activity & .81 & 1.00 & 0.0 \\
\hline
\end{tabular}




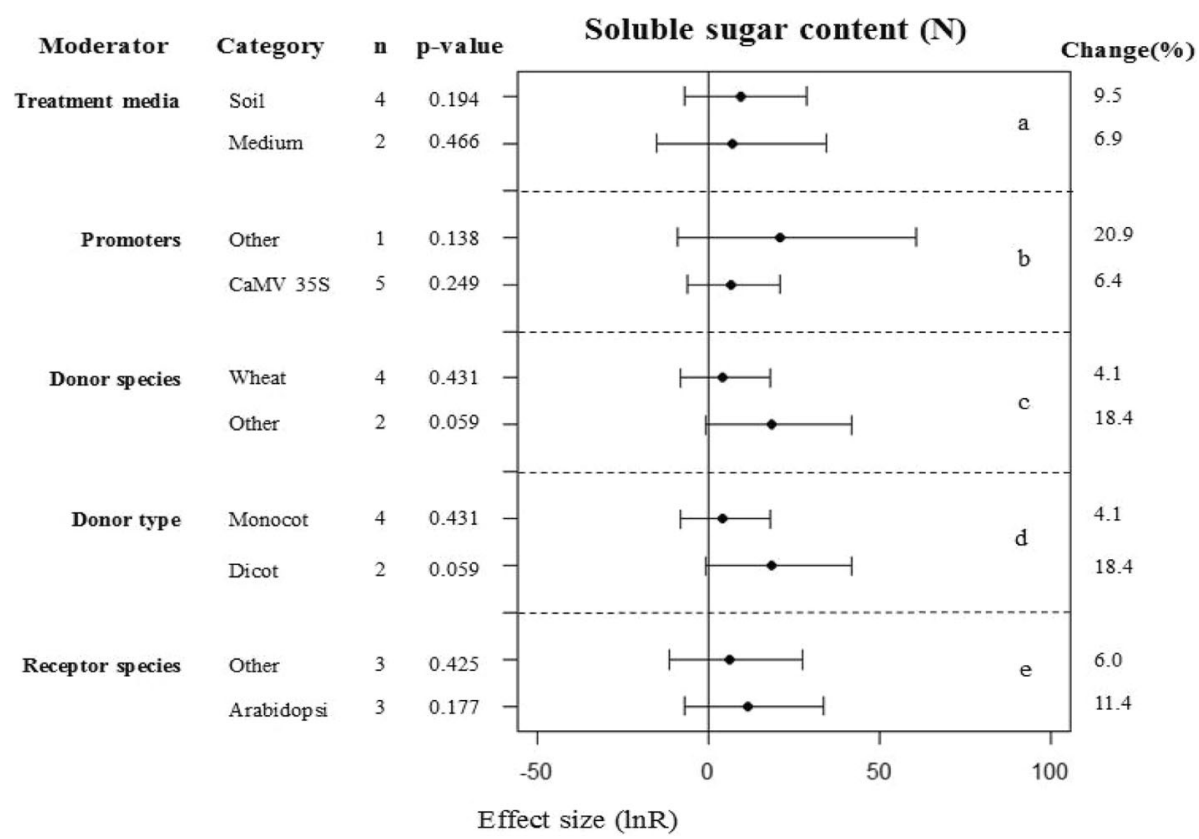

Fig. 8 Subgroup analysis of the effects on soluble sugar content of plants under non-stressed condition. There are five moderators on soluble sugar content in plants in contrast (a-e) and category represents each moderator level

heterogeneity $p$-values were significant $(p<0.10)$ for 2 and 13 of the summary effect sizes under normal and drought conditions, respectively. Due to the different measurement methods used across studies, the heterogeneity between studies was large. Use of the log ratio greatly reduced the heterogeneity of the study (Tables 1,2 ); therefore, it was necessary to convert the data in our meta-analysis and the converted data were used in the integration analysis.

\section{Discussion}

Tang et al. overexpressed WRKY2O in alfalfa and found that the survival rate of transgenic plants was significantly higher $(p<0.01)$ than that of WT plants after 20 $\mathrm{d}$ of drought conditions followed by $7 \mathrm{~d}$ of re-watering [39]. Wang et al. [40] introduced TaWRKY10 into tobacco and found that the survival rate of transgenic plants was much higher than WT plants after 3 weeks of drought treatment. Therefore, it appears that WRKY transcription factors play an important role in plants responses to drought stress. Our meta-analysis showed that with adequate water supply there was no difference in survival between transgenic and WT plants $(p=0.959)$. In contrast, under drought conditions, the survival rate of transgenic plants was higher than that of WT plants $(p=$ 0.000). Most of the researchers in individual studies concluded that their transgenic plants had higher survival rates than the corresponding WT plants after rehydration. Our meta-analysis combined the results of many independent studies to give a confidence interval for this phenomenon. We found that most of the recipient species used to generate the transgenic plants included in our study were dicots (Fig. 3f). The reason for this is probably because model plants are usually dicots such as Arabidopsis or tobacco, and dicots have genomes that are relatively simple and have high transformation efficiencies. Therefore, these species are favored by the majority of researchers when exploring the gene functions. However, because of this favoritism, the results of our study have a risk of bias and care must be taken with extrapolating our results beyond these model plant species.

Plants accumulate large amounts of a variety of osmolytes in response to environmental stress [41]. These include soluble sugar, which is an important non-toxic osmoregulatory substance that is accumulated by plants under osmotic stress $[42,43]$. The soluble sugar content of plants increases with an increase in water stress and this effect becomes more pronounced with increasing water stress. We found that increased soluble sugar content was the main effect associated with WRKY overexpression in transgenic plants and this was most pronounced under normal conditions (Fig. 2). The soluble sugar content, as an osmotic regulator, plays an important role in the resistance of plants to drought stress. Zhu et al. examined the effect of $V v W R K Y 30$ overexpression on the accumulation of soluble sugars under drought stress and found that soluble sugar content increased in both transgenic and WT Arabidopsis plants, with the increase most pronounced in transgenic plants [44]. Ma et al. [45] overexpressed TaWRKY146 in Arabidopsis. Although they found that there was no 
significant in the soluble sugar contents between transgenic and WT plants under normal growth conditions, they found significant differences in drought environment $(p<0.01)$. Other researchers have had similar results [39, 40, 46]. However, Niu et al. found that the soluble sugar contents were not significantly affected in transgenic lines in comparison with control Arabidopsis Col-0 plants exposed to sorbitol stress [47]. We speculate that these conflicting results may be primarily due to differences between the experimental treatments used (Fig. 5b). For example, we found that there was no significant difference in the soluble sugar accumulation between transgenic plants overexpressing WKRYs and WT plants under sorbitol stress $(p=0.066)$.

In general, drought stress inhibits root growth. This effect was can be measured in tolerant genotypes, although the effect is most prominent in sensitive genotypes, such as those of wheat [48]. Zhu et al. [44] overexpressed $V v W R K Y 30$ in grape and found that after $7 \mathrm{~d}$ exposure to $300 \mathrm{mM}$ mannitol the root growth of both the transgenic and WT plants were inhibited, although the effect was greatest in the WT plants. However, Arabidopsis plants overexpressing VvWRKY30 that were grown on basal MS medium without any stress treatment had no significant differences in root growth from that of WT plants. Other researchers have drawn similar conclusions in other species, including cotton $[49-51]$, wheat $[40,52]$, rice $[53,54]$ and soybean $[39,55]$. These findings are also consistent with the results of our meta-analysis. We found that there were no differences in the root growth of transgenic and WT plants under control conditions $(p=0.5)$, but there were significant differences under drought conditions at a near-to-95\% confidence interval $(p=0.181)$. These results suggest that WRKY transcription factors have a positive regulatory effect on the root lengths of transgenic plants and this is a relatively sensitive measurement parameter of plant responses to drought stress. However, not all researchers agree that WRKY transgenic plants have longer root lengths than WT plants under drought conditions [56]. Some consider that WRKY transcription factors have a negative effect on plant root lengths as part of their response to water stress (Fig. 4a). Through further analysis of these studies, we found that exposure to $1-5 \mathrm{~d}$ of drought stress produced this negative effect. Therefore, we propose that the differential responses of WRKY transgenic plants to drought stress detected in different studies is related to the duration of drought stress. Further research is required to test this hypothesis.

When plants are subjected to drought stress they usually have reduced heights in comparison those grown under normal growth conditions. Tang et al. [39] and Niu et al. [47] introduced WRKY2O into alfalfa and TaWRKY2 + TaWRKY19 into Arabidopsis, respectively.
Both studies found that the heights of the transgenic plants were greater than those of WT plants under drought stress. However, Moon et al. [57] found no difference in plant height between transgenic and WT plants. This may be because the sample size in the latter study was smaller than those of the other two studies. From our meta-analysis, we concluded that that transgenic plants were much taller than WT plants under drought conditions at a $90 \%$ confidence interval $(p=0.092)$. However, when evaluating the drought tolerance of transgenic plants expressing WRKY genes, most researchers focus on morphological, physiological and biochemical indexes of plant growth at the seedling stage, and few consider traits such as plant height that are measured in older plants. Consequently, the number of studies that measured plant height that were included in our analysis was relatively small and the results were not significant. Further studies are required to obtain sufficient statistical power to analyze this parameter in the future.

Similar to plant height, the RWC parameter investigated in this study also has the problem that only a small number of studies were available. Drought stress retards plant growth through a cell physiology pathway. The plant RWC reflects the water retention capacity, and drought and dehydration stresses reduce the RWC. In contrast, plants with tolerance to these stresses may exhibit increased RWC [58]. Overexpression of $D n W R K Y 29$ in tobacco and introduction of the maize WRKY58 gene into rice $[40,46]$, significantly increased the RWCs of the transgenic plants under normal growth conditions. However, Sun et al. [59] found no differences in the RWCs of transgenic and WT plants under normal growth conditions. Therefore, even when investigating the same topic, different researchers may reach different or even opposite conclusions. These differences may be due to differences in the research methodologies and materials used. Our meta-analysis showed that there was a significantly difference in the RWC between transgenic and WT plants under control conditions at a 95\% confidence interval $(p=0.009)$. However, it's also due to the small number of studies included in our analysis, more studies are required to support this conclusion.

Besides the phenotypic indicators described above, there are other measured parameters that are sensitive to arid environments. These includes antioxidant defenses (SOD, POD and CAT activities and $\mathrm{H}_{2} \mathrm{O}_{2}$ content), cell membrane physiological indicators (stomatal aperture, electrolyte leakage and malondialdehyde content), compatible solute proline content, chlorophyll participation in photosynthesis (chlorophyll content) and morphological indices (germination, shoot fresh weight) $[44,56,60]$. However, none of these traits were found to be significantly different between transgenic and WT 
plants in our integration analysis and these parameters were not further investigated.

In our study, we found that the type of donor/recipient combination also played a vital role during transgenic plants adaption to drought stressed condition. A significantly greater positive moderator effect was observed when the gene donor and recipient were from the same genus than when the donor and recipient were from the different genus (Fig. 4c). Other researchers drew similar conclusions with us. Dong [38] carried out a meta-analysis of the effect for CBF/DREB TFs in plant adaption to drought stress, and they found that When the gene donors and recipients were composed of different genera, a greater increase in proline levels was observed than if the donor and recipient were from the same genus, no matter if the plants were subjected to nonstressed or stressed conditions. Ma [35] analysed the important role of cation/proton antiporter 1 genes on plants salt tolerance increasing by meta-analysis and found that when gene donors and recipients have been of different genera, the impact of transformation on root $\mathrm{K}^{+} / \mathrm{Na}^{+}$ratio has been about twice as large as when donor and recipient were of the same genus, which can be beneficial to maintain root ionic balance under highsalt condition.

Many researchers $[35,36,61]$ have carried out similar studies to ours that have focused on the differences between transgenic and WT plants under different environmental conditions. However, these studies have not investigated the differential performances of transgenic plants under different water conditions. To comprehensively evaluate the important role of WRKY transcription factors in plant resistance to drought stress, we not only compared the differences between transgenic and WT plants under drought and normal conditions, but we also examined the performance of transgenic plants grown in water-sufficient and waterdeficient conditions. We found that 9 of the 16 measured parameters had positive effects on plant growth under different water conditions, and 7 had negative effects. Eight of the 9 parameters with positive effects and 4 of the 7 parameters with negative effects were statistically significant $(p<0.05$, Fig. 2). Our study shows that WRKY transcription factors play an essential role in plants responses to drought stress. Moreover, our findings will help future researchers to better understand the importance of the WRKY family genes in plants.

\section{Conclusions}

As far as we all know, our study was the first one which examined WRKY transcription factors on plant adapting to drought stress by using meta-analysis. The main results of the present study showed that only one of these parameters was significantly different between transgenic and wild-type plants under drought and control conditions respectively, at a 95\% confidence interval. However, due to the small sample size, more studies were needed here to further explore WRKY-overexpressed plants response to water stressed conditions. We also compared the performance of WRKY-overexpressed plans under drought and control environments. The meta-analysis revealed eleven of the parameters were obviously different in WRKY transgenic plants under drought and control conditions, suggesting that WRKY transcription factors play an important role in plant responses to drought stress. These findings also provide a theoretical basis for further study of the role of WRKY transcription factors in the regulation of plant responses to environmental stress.

\section{Methods}

\section{Data collection}

Endnote X7.1 was used to conduct a search using three electronic databases - PubMed, Web of Science and Springer Link - on 16th April 2018. The keywords ("WRKY transcription factors") and ("drought" or "abiotic stress" or "water deficit") and ("overexpression" or "over-express") and ("crop" or "plant") were used. After a quick appraisal of the title, abstract and keywords of the initial results, a total of 435 studies were selected that were then screened using the following criteria:

a. publication written in English;

b. publication between 2008 and 2018;

c. includes at least some phenotypic evaluation parameters (such as plant height, germination, proline content, and malondialdehyde);

d. the same research is not already published in a different database.

e. it is not a review article or meeting report.

Of the 435 initial studies, 388 did not fully meet the above criteria: 13 studies were excluded because their data were unrelated to plants; 16 were review articles; 109 did not investigate overexpression of WRKY transcription factors; 38 were not related to WRKY transcription factors; 65 were unrelated to drought; and 147 were published in multiple databases. The remaining 47 studies that met the screening criteria were included in our meta-analysis (Fig. 9). Details of the primary studies are provided in Supplementary Materials (Additional file 1).

\section{Effect sizes and moderators}

Several meta-analysis were conducted on parameters that were measured in published studies as adaptations to drought. Figure 1 lists a number of the response 


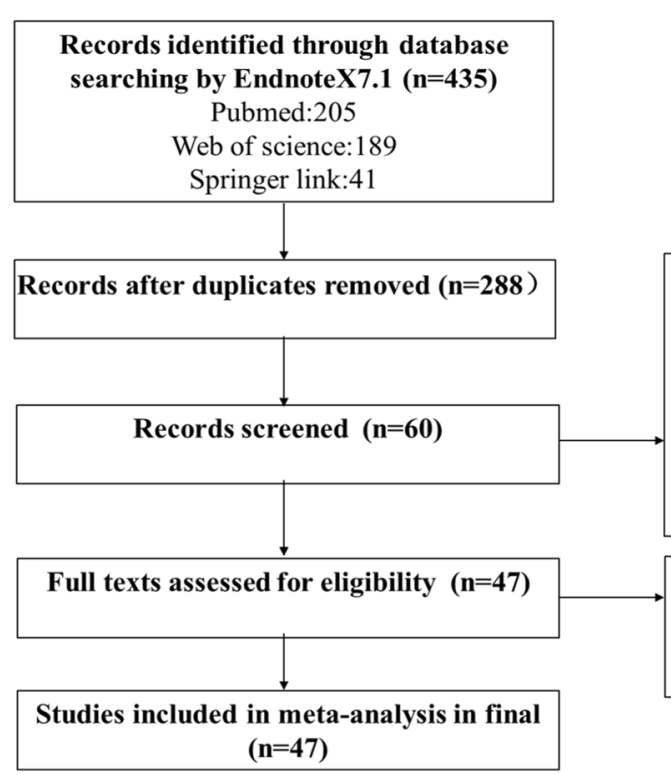

Records excluded with reasons $(n=228)$

-Studies not related to plant experiment

$(\mathrm{n}=13)$

-Studies don't over-expressed genes $(n=106)$

-Studies not related to drought $(n=60)$

-Studies not related to WRKY transcription

factors $(\mathrm{n}=34)$

-Review $(\mathrm{n}=15)$

Full texts excluded with reasons $(n=13)$

-Studies not contain a phenotypic parameters

to evaluate the performance of transgenic and WT plants

Fig. 9 Study Selection Flow Chart

variables commonly measured in plants as adaptations to drought stress. To reduce variation in the meta-analysis, the natural logarithm $(\ln )$ of the response ratio $(R)$, termed effect size, was calculated to measure the response of the plants to drought stress.

$$
\mathrm{Ln} \times \mathrm{R}=\left(\mathrm{X}_{\mathrm{A}} / \mathrm{X}_{\mathrm{b}}\right)
$$

Where $\mathrm{X}_{\mathrm{A}}$ and $\mathrm{X}_{\mathrm{B}}$ represents plants that were transformed with WRKY transcription factors and WT control plants, respectively. This formula describes the effect of overexpressing WRKY transcription factors or not under different environmental conditions. However, when the different effects of overexpressed transcription factors in plants under drought and control conditions were examined, $\mathrm{X}_{\mathrm{A}}$ and $\mathrm{X}_{\mathrm{B}}$ were used to represent transgenic plants subjected to drought and control conditions, respectively.

In addition to the effect size, information gathered from each study was recorded as a moderator that was used to evaluate for heterogeneity within the effect size. The moderators were derived from the following experimental variables: (1) experimental conditions (stress type, stress time, treatment medium); (2) experimental materials (the type and species of the WRKY gene donor and recipient, whether the gene donor and recipient were the same species and type, the seedling age before drought treatment, the type of promoter used); and (3) the number of WRKY genes being tested. Each moderator was set to at least two levels. If certain information was not presented in the original study, the moderator was set to null value and was not used in the classification.

\section{Meta-analysis}

The nlum package of $\mathrm{R}$ Statistical software Version 3.1 (mixed-effects model) was used to calculate the grouped effect sizes [61]. If the 95\% confidence interval of the forest plot overlaps with 0 (that is, the line of the single research level in the forest plot intersects with the vertical line), then the difference between the treatment group and the non-treatment group is considered as not significant. On the contrary, if there is no overlap, then there is $95 \%$ confidence that the difference between the two treatments is significant. The treatments are considered as significantly different from the control groups when $P \leq 0.05$. The smaller the sample size of each trait, the larger the corresponding 95\% confidence interval, and the longer the horizontal line shown in the forest plots. This reduces the reliability of the results. The closer the combined estimate of each trait is to the central axis (small dots on the horizontal line in the figure), the more likely it is that overexpression of the WRKY transcription factor does not affect that parameter. When the small dot is on the left side of the central axis this indicates that the WRKY transcription factor plays a negative regulatory role on the parameter and when it is to the right it represents a positive regulatory effect (these interpretations apply to Figs. 1, 2, 3, 4, 5, 6, 7, 8).

Heterogeneity was assessed using the $Q$ statistic, a measure of weighted squared deviations. The $\mathrm{Q}$ statistic shows the presence of absence of heterogeneity, and is quantified using the descriptive index, $I^{2}$, which estimates the ratio of true heterogeneity to 
total heterogeneity across the observed effect sizes $[62,63]$. Total heterogeneity $(\mathrm{Qt})$ is composed of the expected variation (the within-study heterogeneity, $\mathrm{Qw}$, or sampling error) and the excess variation (the true heterogeneity in effect sizes between studies, Qm) [64]. Assumptions of homogeneity were considered valid when the $p$-values for the Q-test (chi-square test) for heterogeneity were more than 0.1 , and were otherwise rejected. $I^{2}$ is defined as $(\mathrm{Qt}-\mathrm{df}) / \mathrm{Qt}$, where $\mathrm{df}$ represents the degrees of freedom in the expected variation and $\mathrm{Qt}-$ $\mathrm{df}$, represents the true heterogeneity. Negative $I^{2}$ values are set to zero so that $I^{2}$ lies between 0 and $100 \%$. A value of $0 \%$ indicates no true heterogeneity, while positive values indicate true heterogeneity in the data set. Larger $I^{2}$ values reflect a larger proportion of the observed variation that is due to true heterogeneity between the studies [65].

If a single study contained multiple treatments, each treatment was treated as an independent study and so represented an individual unit in the meta-analysis $[35,65,66]$. This approach has been widely used in meta-analysis of plants [67-69]; in particular, for meta-analysis studies that examine the moderators in the original studies [70]. In total, our meta-analysis included a total of 158 independent studies derived from 47 published studies. Each of these are represented by the author + year of the published study and are suffixed with a lower-case letter for studies of plants subjected to drought stress, and with an upper-case letter for studies of plants subjected to normal conditions.

The means and sample sizes for the measured responses were gathered from each study for the treatment and control conditions. If there was no mention of the sample size, we defined it conservatively as $n=1$. For studies that included multiple time points, the measurements taken at every time point were collected. GetData Graph Digitizer was used to determine the actual values when data were only presented in graph form (http:// getdata-graph-digitizer.com) [38].

\section{Additional files}

Additional file 1: The data of original studies on WRKY-overexpression Details on the WRKY-overexpression studies used in the meta-analyses, including each of the moderators used for categorical analyses, the transgenic and WT means $(\mathrm{X})$, sample sizes $(\mathrm{N})$ and standard deviation (SD). (XLSX $106 \mathrm{~kb})$

Additional file 2: Table S1. Heterogeneity statistics for the 16 summary effect sizes under non-stressed condition before data conversed. Qt, total heterogeneity; P, probability that Qt was due entirely to sampling error and not to variation among true effects; $P^{2}$, percentage of heterogeneity due to variation among true effects; Summary effect sizes showing significant heterogeneity among true effects $(p \leq 0.1)$ were shown in bold (Same for Table S2). (DOCX $17 \mathrm{~kb}$ )

Additional file 3: Table S2. Heterogeneity statistics for the 16 summary effect sizes under drought stressed condition before data conversed. (DOCX $17 \mathrm{~kb})$

\section{Abbreviations}

CAT: Catalase; CHC: Chlorophyll content; EL: Electrolyte leakage;

Ger: Germination; $\mathrm{H}_{2} \mathrm{O}_{2}$ : Hydrogen peroxide; MDA: Malondialdehyde; PH: Plant height; POD: Peroxidase; Pro: Proline; RL: Root length; RWC: Relative water content; SA: Stomatal aperture; SFW: Shoot fresh weight;

SOD: Superoxide dismutase; SSC: Soluble sugar content; SV: Survival rate

\section{Acknowledgements}

We thank Shelley Robison, PhD, from LiwenBianji, Edanz Group China (www. liwenbianji.cn/ac), for editing the English text of a draft of this manuscript.

\section{Authors' contributions}

YQH designed the study. Y. G and Y.Q.H drafted the manuscript and substantively revised it. WJP, JTC, LYZ, YFZ and JJG made acquisition of data and performed the analyses. All authors critically revised and provided final approval of this manuscript.

\section{Funding}

This work was supported by a grant from the Hebei Province Science and Technology Support Program, China (14226305D-5, 16226323D-2). The

founding played an important role in data collecting and manuscript editing.

Availability of data and materials

The datasets used for this study are available (included in Additional files).

Ethics approval and consent to participate

Not applicable.

\section{Consent for publication}

Not applicable.

\section{Competing interests}

The authors declare that they have no competing interests.

Received: 22 November 2018 Accepted: 17 July 2019

Published online: 26 July 2019

\section{References}

1. Thu NBA, Hoang XLT, Nguyen T-DH, Thao NP, et al. Differential expression of two-component system-related drought-responsive genes in two contrasting drought-tolerant soybean cultivars DT51 and MTD720 UnderWell-watered and drought conditions. Plant Mol Biol Rep. 2014:33:1599-610.

2. Blum A. Drought resistance, water-use efficiency, and yield potential-are they compatible, dissonant, or mutually exclusive? Aust J Agric Res. 2005;56:1159-68.

3. Gowda VRP, Henry A, Yamauchi A, Shashidhar HE, Serraj R. Root biology and genetic improvement for drought avoidance in rice. Field Crop Res. 2011:122:1-13.

4. Meyre D, Leonardi A, Brisson G, Vartanian N. Drought-adaptive mechanisms involved in the escape/tolerance strategies of Arabidopsis Landsberg erecta and Columbia ecotypes and their F1 reciprocal progeny. J Plant Physiol. 2001;158:1145-52.

5. Sinclair T, Muchow R. System analysis of plant traits to increase grain yield on limited water supplies. Agron J. 2001;93:263-70.

6. Yamauchi A, Pardales Jr JR, Kono Y. Root system structure and its relation to stress tolerance. In: Ito O, Katayama K, Johansen C, et al, editors. Roots and nitrogen in cropping systems of the semi-arid tropics. Patancheru, Andhra Pradesh, India; 1994. p. 211-233.

7. Serraj R, Sinclairt TR. Osmolyte accumulation: can it really help increase crop yield under drought conditions? Plant, Cell and Environment. 2002;25:333-41.

8. Scandalios JG. Oxidative stress: molecular perception and transduction of signals triggering antioxidant gene defenses. Braz I Med Biol Res. 2005;38:995-1014

9. Rivero R, Kojima M, Gepstein A, Sakakibara H, Mittler R, Gepstein S, Blumwald E. Delayed leaf senescence induces extreme drought tolerance in a flowering plant. Proc Natl Acad Sci U S A. 2007;104:19631-6.

10. Jaleel CA, Gopi R, Sankar B, Manivannan P, Kishorekumar A, et al. Studies on germination, seedling vigour, lipid peroxidation and proline metabolism in Catharanthus roseus seedlings under salt stress. S Afr J Bot. 2007;73:190-5. 
11. Lei Y-B, Yin C-Y, Li C-Y. Differences in some morphological, physiological, and biochemical responses to drought stress in two contrasting populations of Populus przewalskii. Physiol Plantarum. 2006;127:182-91.

12. Fu G-F, Song J, Xiong J, Li Y-R, Chen H-Z, Le M-K, Tao L-X. Changes of oxidative stress and soluble sugar in anthers involve in Rice pollen abortion under drought stress. Agric Sci China. 2011;10:1016-25.

13. Fournier J, Roldán Á, Sánchez C, Alexandre G, Benlloch M. K+ starvation increases water uptake in whole sunflower plants. Plant Sci. 2005;168:823-9.

14. Li Y. Kinetics of the antioxidant response to salinity in the halophyte Limonium bicolor. Plant Soil Environ. 2008;54:493-7.

15. Sankar B, Jaleel CA, Manivannan P, Kishorekumar A, et al. Drought-induced biochemical modifications and proline metabolism in Abelmoschus esculentus (L.) Moench. Acta Botanica Croatica. 2007;66:43-56.

16. Agarwal $P$, Agarwal $P$, Reddy $M$, Sopory $S$. Role of DREB transcription factors in abiotic and biotic stress tolerance in plants. Plant Cell Rep. 2006;25:1263-74.

17. Bae H, Kim S, Kim M, Sicher R, Lary D, et al. The drought response of Theobroma cacao (cacao) and the regulation of genes involved in polyamine biosynthesis by drought and other stresses. Plant Physiol Biochem. 2008:46:174-88.

18. Broin M, Cuiné S, Peltier G, Rey P. Involvement of CDSP 32,a droughtinduced thioredoxin,in the response to oxidative stress in potato plants. Federation European Biochem Soc. 2000;467:245-8.

19. Kavar T, Maras M, Kidrič M, Šuštar-Vozlič J, Meglič V. Identification of genes involved in the response of leaves of Phaseolus vulgaris to drought stress. Mol Breed. 2008:21:159-72

20. Motoaki S, Ayako K, Kazuko Y, Kazuo S. Molecular responses to drought, salinity and frost: common and different paths for plant protection. Curr Opin Biotechnol. 2003;14:194-9.

21. Tyerman $\mathrm{S}$, Niemietz $\mathrm{C}$, Bramley $\mathrm{H}$. Plant aquaporins: multifunctional water and solute channels with expanding roles. Plant, Cell Environ. 2002;25:173-94.

22. Huang D-Q, Wu W-R, Abrams S, Cutler A. The relationship of droughtrelated gene expression in Arabidopsis thaliana to hormonal and environmental factors. J Exp Bot. 2008:59:2991-3007.

23. Rushton P, Somssich IE. Transcriptional control of plant genes responsive to pathogens. Curr Opin Plant Biol. 1998;1:311-5.

24. Chinnusamy V, Zhu J-H, Zhu J-K. Gene regulation during cold acclimation in plants. Physiol Plantarum. 2006;126:52-61

25. Chen W, Zhu T. Networks of transcription factors with roles in environmental stress response. Trends Plant Sci. 2004;9:12.

26. Wan $Y-Q$, Mao M-Z, Wan D-L, Yang Q, Yang F-Y, et al. Identification of the WRKY gene family and functional analysis of two genes in Caragana intermedia. BMC Plant Biol. 2018;18:31.

27. Jaffar MA, Song A, Faheem M, Chen S, Jiang J, Liu C, et al. Involvement of CmWRKY10 in drought tolerance of Chrysanthemum through the ABA-signaling pathway. Int J Mol Sci. 2016;17:693.

28. Liu H, Han Y, Yang W, Zhang A, Liu D, Li S. Ectopic expression of a grapevine transcription factor VVWRKY11 contributes to osmotic stress tolerance in Arabidopsis. Mol Biol Rep. 2011;38:417-27.

29. Wu X-L, Shiroto Y, Kishitani S, Ito Y, Toriyama K. Enhanced heat and drought tolerance in transgenic rice seedlings overexpressing OsWRKY11 under the control of HSP101 promoter. Plant Cell Rep. 2009;28:21-30.

30. Cai R-H, Zhao Y, Wang Y-F, Lin Y-X, Peng X-J, Li Q, Chang Y-W, et al. Overexpression of a maize WRKY58 gene enhances drought and salt tolerance in transgenic rice. Plant Cell Tiss Org. 2014;119:565-77.

31. Ding W-W, Fang W-B, Shi S-Y, Zhao Y-Y, Li X-J, Xiao K. Wheat WRKY type transcription factor gene TaWRKY1 is essential in mediating drought tolerance associated with an ABA-dependent pathway. Plant Mol Biol Rep. 2016:34:1111-26.

32. Xu Q, Feng W-J, Peng H-R, Ni Z-F, Sun Q-X. TaWRKY71, a WRKY transcription factor from wheat, enhances tolerance to abiotic stress in transgenic Arabidopsis thaliana. Cereal Res Commun. 2014;42:47-57.

33. Hedges $L$, Gurevitch J, Curtis $P$. The meta-analysis of response ratios in experimental ecology. Ecological Society of America. 1999:80:1150-6.

34. Wang J-Y, Xiong Y-C, Li F-M, Siddique K, Turner N. Effects of Drought Stress on Morphophysiological Traits, Biochemical Characteristics, Yield, and Yield Components in Different Ploidy Wheat: A Meta-Analysis. Adv Agron. 2017:140-69.

35. Ma Y-C, Aug R-M, Dong C, Cheng Z-M. Increased salt tolerance with overexpression of cation/proton antiporter 1 genes: a meta-analysis. Plant Biotechnol J. 2017;15:162-73.
36. Augé RM, Toler HD, Saxton AM. Arbuscular mycorrhizal symbiosis and osmotic adjustment in response to $\mathrm{NaCl}$ stress: a meta-analysis. Front Plant Sci. 2014;5:562.

37. Berry JA, Raison JK, et al. Responses to the physical environment. In: Lange OL, Nobel PS, Osmond CB, Ziegler H, editors. Physiological plant ecology I. N Y; 1981. 12:277-328.

38. Dong C, Ma Y, Wisniewski M, Cheng Z-M. Meta-analysis of the effect of overexpression of CBF/DREB family genes on drought stress response. Environ Exp Bot. 2017:142:1-14.

39. Tang L-L, Cai H, Zhai H, Luo X, Wang Z-Y, Cui L, Bai X. Overexpression of Glycine soja WRKY20 enhances both drought and salt tolerance in transgenic alfalfa (Medicago sativa L.). Plant Cell Tiss Org. 2014;118:77-86.

40. Wang C, Deng P-Y, Chen L-L, Wang X-T, Ma H, Hu W, Yao N-C, et al. A wheat WRKY transcription factor TaWRKY10 confers tolerance to multiple abiotic stresses in transgenic tobacco. PLoS One. 2013;8:6.

41. Serraj $R$, Sinclair $T$. Osmolyte accumulation: can it really help increase crop yield under drought conditions? Plant, Cell Environ. 2002;25:333-41.

42. Nanjo T, Kobayashi M, Yoshiba Y, Sanada Y, Wada K, Tsukaya H, et al. Biological functions of proline in morphogenesis and osmotolerance revealed in antisense transgenic Arabidopsis thaliana. Plant J. 1999;18:185-93.

43. Yang Z, Xu L, Yu J-J, DaCosta M, Huang B. Changes in carbohydrate metabolism in two Kentucky bluegrass cultivars during drought stress and recovery. J Am Soc Hortic Sci. 2013;138:24-30.

44. Zhu D, Che Y, Xiao P, Hou L, Guo Y, Liu X. Functional analysis of a grape WRKY30 gene in drought resistance. Plant Cell Tiss Org. 2018;132:449-59.

45. Ma J-H, Gao X-L, Liu Q, Shao Y, Zhang D-J, Jiang L-N, Li C-X. Overexpression of TaWRKY146 increases drought tolerance through inducing stomatal closure in Arabidopsis thaliana. Front Plant Sci. 2017;8:2036.

46. Wang $X-T$, Zeng J, Li Y, Rong X-L, Sun J-T, Sun T, Li M, Wang L-Z, Feng $Y$, et al. Expression of TaWRKY44, a wheat WRKY gene, in transgenic tobacco confers multiple abiotic stress tolerances. Front Plant Sci. 2015;6:615.

47. Niu C-F, Wei W, Zhou Q-Y, Tian A-G, Hao Y-J, Zhang W-K, Ma B-A, Lin Q, et al. Wheat WRKY genes TaWRKY2 and TaWRKY19 regulate abiotic stress tolerance in transgenic Arabidopsis plants. Plant Cell Environ. 2012;35:1156-70.

48. Piro G, Leucci MR, Waldron K, Dalessandro G. Exposure to water stress causes changes in the biosynthesis of cell wall polysaccharides in roots of wheat cultivars varying in drought tolerance. Plant Sci. 2003;165:559-69.

49. Yan Y, Jia H-H, Wang F, Wang C, Liu SC, Guo X-Q. Overexpression of GhWRKY27a reduces tolerance to drought stress and resistance to Rhizoctonia solani infection in transgenic Nicotiana benthamiana. Front Physiol. 2015;6:265.

50. Chu X-Q, Wang C, Chen X-B, Lu W-J, Li H, Wang X-L, Hao L-L, et al. The cotton WRKY gene GhWRKY41 positively regulates salt and drought stress tolerance in transgenic Nicotiana benthamiana. PLoS One. 2015;10:12.

51. Liu X-F, Song Y-Z, Xing F-Y, Wang N, Wen F-J, et al. GhWRKY25, a group I WRKY gene from cotton, confers differential tolerance to abiotic and biotic stresses in transgenic Nicotiana benthamiana. Protoplasma. 2016;253:1265-81.

52. He G-H, Xu J-Y, Wang Y-X, Liu J-M, Li P-S, Chen M, et al. Drought-responsive WRKY transcription factor genes TaWRKY1 and TaWRKY33 from wheat confer drought and/or heat resistance in Arabidopsis. BMC Plant Biol. 2016;16:116.

53. Song Y, Jing S-J, Yu D-Q. Overexpression of the stress-induced OsWRKY08 improves osmotic stress tolerance in Arabidopsis. Chin Sci Bull. 2009:54:4671-8. https://doi.org/10.1007/s11434-009-0710-5.

54. Qiu Y-P, Yu D-Q. Over-expression of the stress-induced OsWRKY45 enhances disease resistance and drought tolerance in Arabidopsis. Environ Exp Bot. 2009;65:35-47.

55. Luo X, Bai X, Sun X-L, Zhu D, Liu B-H, Ji W, Cai H, Cao L, Wu J, et al. Expression of wild soybean WRKY20 in Arabidopsis enhances drought tolerance and regulates ABA signalling. J Exp Bot. 2013;64:2155-69.

56. Yan $\mathrm{H}-\mathrm{R}$, Jia H-H, Chen X-B, Hao L-L, An H-L, Guo X-Q. The cotton WRKY transcription factor GhWRKY17 functions in drought and salt stress in transgenic Nicotiana benthamiana through ABA signaling and the modulation of reactive oxygen species production. Plant Cell Physiol. 2014;55:2060-76.

57. Moon SJ, Han SY, Kim DY, Kim BG, Yoon IS, Shin D, Kwon HB, Byun MO. Ectopic expression of CaWRKY1, a pepper transcription factor, enhances drought tolerance in transgenic potato plants. Journal of Plant Biology. 2014;57:198-207.

58. Chen L, Chen F-D, Chen Y, Jiang J-F, Guan Z-Y, Chen S-M, Fang W-M. The constitutive expression of Chrysanthemum dichrum ICE1 in Chrysanthemum grandiflorum improves the level of low temperature, salinity and drought tolerance. Plant Cell Rep. 2012;31:1747-58. 
59. Sun J, Hu W, Zhou R, Wang L, Wang X, Wang Q, Feng Z, Li Y, Qiu D, et al. The Brachypodium distachyon BdWRKY36 gene confers tolerance to drought stress in transgenic tobacco plants. Plant Cell Rep. 2015;34:23-35.

60. Zhao J, Zhang X-M, Guo R-R, Wang Y-Q, Guo C-L, Li Z, Chen Z-P, Gao H, Wang X-P. Over-expression of a grape WRKY transcription factor gene, VIWRKY48, in Arabidopsis thaliana increases disease resistance and drought stress tolerance. Plant Cell Tiss Org. 2018;132:359-70.

61. Petersen S, Højberg O, Poulsen M, Schwab C, Eriksen J. Methanogenic community changes, and emissions of methane and other gases, during storage of acidified and untreated pig slurry. J Appl Microbiol. 2014:117:160-72.

62. Huedo-Medina TB, Sánchez-Meca J et al. Assessing heterogeneity in meta-analysis: Q statistic or $P^{2}$ index? Psychological methods; 2006,11:193.

63. Higgins J, Thompson S. Quantifying heterogeneity in a meta-analysis. Stat Med. 2002;21:1539-58.

64. Borenstein M, Hedges LV, Higgins JPT, et al. Introduction to Meta-Analysis. John Wiley \&Sons. West Sussex. 2011:107-25.

65. Oh S-J, Kwon C, Choi D, Song S, Kim J. Expression of barley HvCBF4 enhances tolerance to abiotic stress in transgenic rice. Plant Biotechnol J. 2007:5:646-56

66. Zhang X, Liu X-X, Wu L, Yu G-H, Wang X, Ma H-X. The SsDREB transcription factor from the succulent halophyte Suaeda salsa enhances abiotic stress tolerance in transgenic tobacco. International Journal of Genomics. 2015:2015:1-13.

67. Holmgren $T$, Hallgren $H$, Öberg B, Adolfsson L, Johansson K. Effect of specific exercise strategy on need for surgery in patients with subacromial impingement syndrome: randomised controlled study. BMJ. 2012;344:e787.

68. Klu W, Qaim M. A meta-analysis of the impacts of genetically modified crops. PLoS One. 2014;9:-e111629.

69. Wujeska A, Bossinger G, Tausz M. Responses of foliar antioxidative and photoprotective defence systems of trees to drought: a meta-analysis. Tree Physiol. 2013;33:1018-29.

70. Lehmann A, Rillig M. Arbuscular mycorrhizal contribution to copper, manganese and iron nutrient concentrations in crops e a meta-analysis. Soil Biol Biochem. 2015;81:147-58.

\section{Publisher's Note}

Springer Nature remains neutral with regard to jurisdictional claims in published maps and institutional affiliations.

Ready to submit your research? Choose BMC and benefit from:

- fast, convenient online submission

- thorough peer review by experienced researchers in your field

- rapid publication on acceptance

- support for research data, including large and complex data types

- gold Open Access which fosters wider collaboration and increased citations

- maximum visibility for your research: over $100 \mathrm{M}$ website views per year

At BMC, research is always in progress.

Learn more biomedcentral.com/submissions 